\title{
Research Series on the Industry Development of International Tourism Island-The Problem and Suggestion on Agritainment in Hainan
}

\author{
Yihe Huang \\ Hainan Institute of Science and Technology, Haikou, China
}

\begin{abstract}
Due to the establishment of Hainan international tourism island and the fulcrum position of the maritime silk road, the tourism industry of Hainan has made a leaping development, and especially the "agritainment"--rural tourism, is ushered in new opportunities and challenges. Starting from the problems existing in "agritainment"--rural tourism, the paper proposes some corresponding methods and measures appropriately, to promote the healthy and standardized development of "agritainment" rural tourism in Hainan.
\end{abstract}

\section{Key words-Hainan; Agritainment; Problem; Suggestion}

In March 5, 2008, the State Council approved Hainan "to further play the advantages of the special economic zone, actively explore the opening up and reform of institutional mechanisms in the tourism industry, and test first". On this basis, Hainan comprehensively accelerate the construction plan of "international tourism island", which means focus on the opening of the tourism industry and implement the opening policy to the foreigners mainly characterized by "visa free, zero tariff, traffic rights" in the particular island region, to promote the international process of Hainan's tourism services, and make it become a unique and influential international tourism resort.

In the industrial system of the construction of Hainan international tourism island, agritainment is undoubtedly a bright spot. As a new form of tourism leisure, agritainment is a kind of leisure travel mode that the farmers provide to the city people to return the nature to relax and cheer themselves. Usually, the farmers use agricultural products with local and national characteristics to meet the needs of the guests. Since the cost is low, the consumption is not high. Besides, for always being surrounded by beautiful natural or pastoral scenery, it can meet and the spirit need of modern people and is highly welcomed by many people in the city. In recent years, under the strong support of Hainan provincial and municipal government and the relevant departments, and relying on the local beautiful natural environment and rich natural resources, many rural areas in Hainan actively develop the agritainment, which not only enables the tourists to relax in the experience of "living in the farm house, eating the farm meal, doing the farm work, learning the farm art, and enjoying the farm entertainment", but also has a good effect on promoting the adjustment of rural industrial structure, increasing the income of farmers, promoting the construction of rural spiritual civilization and the construction of basic facilities.
Though the vigorous development of agritainment in our province has promoted the construction of new countryside, we should clearly recognize the shortcomings and disadvantages during its development. Due to the restriction of subjective and objective factors, agritainment in our province is faced with many problems: such as single type and lack of new ideas and repeated low level developing in tourism products; backward management idea and weak brand awareness; unreasonable layout; poor infrastructure and sanitation and lack of safety protection; indifferent environmental awareness and serious environmental pollution; lack of employees training and low service level. Moreover, less prominent features and lack of participatory and experiential activities and many other issues, affect and restrict the healthy and rapid development of Hainan's agritainment.

\section{EXISTING PROBLEMS}

A. Tourism products---lack of new ideas, single type, and low-level repeat developing.

At present, the main body of the agritainment is farmers, whose heavy imitation and less innovation leads to the serious tendency of running the same product. For example, Volcano Spring leisure farm near the intersection of Nanhai Avenue and green corridor in Haikou City, Lvfeng village in Kang'an village, Xiuying District, Haikou City, Nanhai Leisure Farm in Nanhai Avenue in the direction of Xiuying Road to Laocheng town, Dongpo farm in Jiazi town, Qiongshan District, Haikou City, Hainan Fengsheng vanilla park in the town of Sanjiang---30 km from Haikou, and Zongwangyuan leisure farm in Chengmai County, are all the places that provide recreational sightseeing, fishing, picking, chess, mountain climbing, working in farmland and enjoying green food etc. For the lack of new ideas, low level repeated developing exist in these projects commonly.

\section{B. Backward management idea and weak brand awareness}

Features and brand is the key factor to attract visitors. At present, most of the operators of agritainment take passive management following the same pattern without their own characteristics. The connotations of ecological culture, local culture, folk culture haven't been exploited. At the same time, they lack the awareness of the market, and sales promotion through the internet should be taken into consideration. In addition, the agritainment should strengthen the joint development with the surrounding 
tourism resources, and co-establish the brand to achieve mutually beneficial win-win effect.

\section{Unreasonable layout}

For its planning and design layout being valued by local government and relevant departments, the overall situation of rural tourism is good. However, with the characteristics of dispersion and looseness, many standard management is a kind of post management as it is difficult to control in advance, which cause the lack of necessary scientific basis in the layout of some agritainment, and the existence of disorderly construction and development in a certain range.

\section{Poor infrastructure and sanitation, and lack of safety protection}

The main characteristics of agritainment is the operation without hygiene license. For example, kitchen equipment is simple, basic disinfection facilities is lack, sewage can be seen everywhere, and even there is the shadow of the mouse; raw and cooked food and dishes are jumbled together and cutting boards for raw food and cooked food is not divided; dead angle of hygiene exist in toilet and courtyard and simple toilet, water tank, sty and fold are adjacent to the kitchen; purchasing channels of some food is in disorder, and individual farmers purchase the main and auxiliary material making cold dishes such as vermicelli, potato, soybean skin from small workshop. All of the above make the health conditions worrying. On the use of electricity, the increase of household electrical appliances caused by agritainment add to the electrical workload and make the leakage and fire easy because some of the rural electric wire circuit haven't been transformed and maintained for a long-term. All kinds of debris around the house and the lack of fire-fighting facilities make the reception point full of fire risk. There is still no necessary rules and regulations about how to protect the safety of tourists' lives and property for these agritainment reception point.

\section{E. Indifferent environmental awareness and serious environmental pollution}

Owing to the owners' indifferent environmental awareness and backward management level, the service class of agritainment located in the picturesque scenery of the underdeveloped areas is low. With the increasing number of reception, sewage disposal and fire safety hazards increase accordingly. In order to attracts customers, some farmhouses install the swings, slides, seesaws and other recreational facilities. These facilities basically have problems more or less like corrosion of components, connecting parts easy to slip, cement plate with cracks, which is easy to cause skin trauma or more damage to the tourist. Due to the special geographical position of being built mostly along the river (ditch, canal, or weir) or near to the highways and railways, the farmhouse has no fixed security personnel, and lack indicative signs to some key parts. If parents were engaged in their own cards or tea, children are prone to injury for lack of supervision. And if there is an accident, on account of the special management status of agritainment, it will be very troublesome for the two sides to resolve disputes. In addition, the no tied dogs, cats, chicken and other animals, can bring unexpected harm to the children easily for slightest carelessness.

\section{F. Lack of employees training, and low service level}

The servers of rural tourism are mostly householder themselves or their relatives, many of which work without rigorous physical examination and health certificate. In addition, for the reason of no professional training, the vast majority of the servers have no professional service abilities, and be unable to run the business expertly while receiving a large number of customers, especially foreign guests. In actual operation, the local farmers are not only administrators, but also workers. The extensive management leads to a vicious spiral of " light management, low quality, low income", and restrict the development of farmhouse leisure tourism.

\section{SUGGESTIONS FOR IMPROVEMENT}

In order to promote the more rapid and healthy development of the burgeoning agritainment in our province, the following suggestions are put forward according to the present situation and problems:

\section{A. Rationalizing the management system of agritainment}

Rationalizing the management system of agricultural tourism as soon as possible is the key to activate the rural tourism's development. From the present situation of agritainment, it is generally developed and constructed by the farmers spontaneously. On the examination, approval, planning and construction of agritainment, the tourism sector basically can not intervene, and make a good industry management and external publicity. Therefore, it is suggested that the tourism administration department participate in the record and approval of agritainment from the planning, guidance and standardizing the management, to truly form the industry counterpart management, and promote the suburban and rural agritainment tourism management throughout the province.

\section{B. Broadening the sources of funds, to increase capital investment}

For the lack in capital mostly input by the farmers' spontaneously, the economic strength of current development and construction of the rural tourism is generally poor. Therefore, we should broaden the investment channels, intensify the reform of tourism investment and financing system, implement diversified investment channels combining government investment, mass investment and social investment, to continuously strengthen the force of market exploitation and solve prominent problems facing the development of agricultural tourism. At the same time, the government should introduce the real operational preferential policy specifically for the phenomenon of agritainment, to support its rapid development.

\section{Highlighting the characteristics and details, to create tourism brand}

Highlight the characteristics, to create a rural leisure tourism brand, and constantly innovate the way and method of tourism promotion activities. By the various means of propaganda such as setting up thematic publicity programs and columns, promotion, seminars, forum, tourist routes recommendation and "farmer mailbox", 
strengthen the image design packaging, publicity and promotion work, to show the industry style, improve the visibility and appeal, and strengthen the propaganda of overall image. Meanwhile, by making full use of local specialty resources, traditional diet and technology, vigorously develop rural leisure tourism products, to meet the consumer demand of different levels.

\section{Continuously improving the management level and quality of personnel}

Because of the lack of high level professional management personnel and high-quality workers and the extensive, lax management, the management level and the reception level of rural tourism are relatively backward, which will seriously affect the development of agricultural tourism if it goes on in this way. So, all parts should pay attention to the construction of a high level, high quality management team and employees by various ways and methods like combining centralized training and "going out" to learn foreign advanced experience, to continuously enhance the quality of employees, improve the management level, and pay attention to cultivate the best local window image to promote the comprehensive improvement with the power of an example.

\section{E. Planning scientifically, to develop tourism projects rationally}

Because regional and folk culture difference is the highlight of the agritainment tourism, it is very important to set up the tourism project in the light of local conditions, and to make scientific planning and rational development. Countryside with high quality of tourism resources.

good transportation condition, and near the tourism hot spots can be added to the key development base of agritainment tourism. If there is condition, it can be connected and formed scale management, to become bigger and stronger, only through which more options can be provided to attract more people.

\section{$F$. Enhancing the environmental protection awareness}

To scientifically plan the agritainment tourism, the carrying capacity of the local environment should be taken into full consideration and the awareness of resource conservation and environmental protection should be strengthened. Planning and design should adjust measures to local conditions highlighting the characteristics.

make efforts in housing construction, environmental construction, activity design, energy saving and environmental protection and other aspects by combining with the local leading industry and natural human environment, to do fine "farmhouse" brand.

\section{G. Adapting to the development of international tourism}

All road signs should be internationalized. The highest state of Hainan international tourism island should be a tour with zero barriers for the people all over the world. Due to the free travel based, agritainment should take the convenience of tourists as the criterion, strengthen the internationalization of traffic marking standard, to let Hainan international tourism island be worthy of the name.

At present, agritainment has become one of the first choices of holiday leisure for urban people living in the hustle downtown, with tourists mainly being concentrated in China. Among the Chinese tourism resources that overseas visitors are most interested, landscape scenery, cultural relics and customs and customs of the first three. In addition, according to expert's investigation, the tourists of Britain, the United States, Japan, Germany, France, Australia make without exception "interacting with the local people, to understand the local culture and lifestyle" as one of the three major motives of outbound tourism. The tourism products of agritainment are just in line with the needs and desires of foreign tourists. We believe, under the correct leadership of the provincial, municipal and all levels of government, and with the joint effort of the colleagues of the our province's tourism industry, the agritainment leisure tour of our province is sure to create our own brand by making full use of characteristics, and bore an imprint in the process of creating the international tourist island.

\section{REFERENCES}

[1] Problems and Suggestions on the Development of Rural Tourism in Changshou District (Research Information). Chongqing Changshou Website Portal (March-10-2008).

[2] W, W., \& X, X (2008). Problems and Suggestions on the Existence of "Rural Tourism". Linhai News Network (Augest-5-2008).

$\mathrm{s}$ and Countermeasures of "Rural Tourism" in Chun'an County. Hangzhou Administration for Industry and Commerce Website (December-17-2008).

[4] L, S., \& Q, L.Y.,\& H,F.C. (2012). Research on Positioning and Mode Selection of Government Function. Tourism Tribune, 27 (2),

[5] Guidance for 13th Five-Year Plan of Hainan Province.

[6] Outline of the Overall Planning of Hainan Province (2015-2030).

[7] D, L. Y., \& L, Q. L.(2010). A Preliminary Study on the Development of Large Agricultural Tourism in Hainan in the Context of International Tourism Island Construction. Tropical Agricultural Science,(06).

[8] Z, C. X. (2010). A Research on the Construction of Hainan International Tourism Island. Green Science and Technology,

[9] A, Y. M. (2010). Countermeasures of Improving the Quality of Tourism Services in Hainan in the Context of International Tourism Island. Tourism Forum, (04).

[10] S, J. X.(2011). Discussion and Reflection on the Development of Leisure Tourism in Hainan. Study on Tourism Economy, 